\title{
CCAAT/enhancer binding protein $\varepsilon$ is a potential retinoid target gene in acute promyelocytic leukemia treatment
}

\author{
Dorothy J. Park, ${ }^{1}$ Alexey M. Chumakov, ${ }^{1}$ Peter T. Vuong, ${ }^{1}$ Doris Y. Chih, ${ }^{1}$ \\ Adrian F. Gombart, ${ }^{1}$ Wilson H. Miller, Jr., ${ }^{2}$ and H. Phillip Koeffler ${ }^{1}$

\begin{abstract}
${ }^{1}$ Division of Hematology/Oncology, Cedars-Sinai Medical Center, University of California-Los Angeles School of Medicine, Los Angeles, California 90048, USA

${ }^{2}$ Lady Davis Institute for Medical Research, McGill University, Montreal, Quebec H3T 1E2, Canada

Address correspondence to: Dorothy J. Park, Division of Hematology/Oncology, Cedars-Sinai Medical Center, University of California-Los Angeles School of Medicine, 8700 Beverly Boulevard, B-210, Los Angeles, California 90048, USA.
\end{abstract} \\ Phone: (310) 855-4502; Fax: (310) 659-9741; E-mail: parkd@ucla.edu.
}

Received for publication January 22, 1998, and accepted in revised form March 19, 1999.

\begin{abstract}
The CCAAT/enhancer binding protein $\varepsilon(\mathrm{C} / \mathrm{EBP} \varepsilon)$ is a nuclear transcription factor expressed predominantly in myeloid cells and implicated as a potential regulator of myeloid differentiation. We show that it was rapidly induced in the acute promyelocytic leukemia (APL) cell line NB4 during granulocytic differentiation after exposure to retinoic acid (RA). Our data suggest that induction of C/EBPE expression was through the retinoic acid receptor $\alpha(\operatorname{RAR} \alpha)$ pathway. Reporter gene studies showed that $\mathrm{C} / \mathrm{EBP} \varepsilon$ promoter/enhancer activity increased in a retinoid-dependent fashion via the retinoic acid response element (RARE) present in the promoter region of C/EBPE. The RA-induced expression of C/EBPE markedly increased in U937 myelomonoblasts that were induced to express promyelocytic leukemia/RAR $\alpha$ (PML/RAR $\alpha$ ), but not in those induced to express promyelocytic leukemia zinc finger/RAR $\alpha$ $(\mathrm{PLZF} / \mathrm{RAR} \alpha)$. In retinoid-resistant APL cell lines, C/EBPE either is not induced or is induced only at very high concentrations of RA $\left(\geq 10^{-6} \mathrm{M}\right)$. In addition, forced expression of C/EBP $\varepsilon$ in the U937 myelomonoblastic leukemia cells mimicked terminal granulocytic differentiation, including morphologic changes, increased $\mathrm{CD} 11 \mathrm{~b} / \mathrm{CD} 66 \mathrm{~b}$ expression, and induction of secondary granule protein expression. Our data strongly suggest that C/EBPE is a downstream target gene responsible for RA-induced granulocytic differentiation of APL cells.
\end{abstract}

J. Clin. Invest. 103:1399-1408 (1999).

\section{Introduction}

Evidence from studies of both normal and leukemic cells suggests that myeloid hematopoiesis is a multistage developmental process requiring coordinate expression of multiple genes by various lineage-restricted transcription factors. Consequently, myeloid-specific transcription factors play a critical role in myelopoiesis, and the failure to induce these transcription factors in a timely fashion may result in loss of capacity for terminal differentiation and the development of a leukemic clone. However, the mechanism that regulates granulocytic differentiation of hematopoietic stem cells at the molecular level is not clearly understood.

Retinoids and their nuclear receptors appear to have multiple functions in the regulation of normal cellular differentiation (1). The retinoic acid receptor (RAR) forms a heterodimeric complex with the retinoid $\mathrm{X}$ receptor $(\mathrm{RXR})$ and has an important function in the transactivation of myeloid-specific genes $(2,3)$. Recently, all-trans retinoic acid (ATRA) has become a standard therapy for the induction of remissions in patients with acute promyelocytic leukemia (APL) $(4,5)$. Among the naturally occurring retinoids, ATRA is considered a potent modulator of cell growth. ATRA binds RAR but does not bind RXR; 9-cis retinoic acid (RA), a naturally occurring RA double-bond isomer, on the other hand, can bind to both RAR/RXR and RXR/RXR receptors (6, 7). Additionally, by using analogues that are selective for
$\mathrm{RAR} / \mathrm{RXR}$ and $\mathrm{RXR} / \mathrm{RXR}$ receptors, as well as analogues that are selective for isomers $\operatorname{RAR}(\alpha, \beta, \gamma)$ and $\operatorname{RXR}(\alpha, \beta$, $\gamma$ ), the molecular pathways that are involved in differentiation can be mapped more precisely.

The ligand-receptor complexes transactivate downstream genes that have RAR recognition sequences $(8,9)$. Activation of transcription by nuclear receptor homodimers or heterodimers in response to ligands requires binding of the nuclear receptors to retinoic acid response elements (RAREs) in target genes that generally contain 2 core recognition sequences, or "half-sites" (AGGTCA), that are separated by 5 nucleotides contacted by each of the DNA-binding domains of the dimer. Although RAR and RXR have been shown to be important in the differentiation of myeloid cells, their downstream target genes involved in this process are unknown.

APL is a subtype of myeloid leukemia characterized by a unique translocation between chromosomes 15 and 17 , resulting in a fusion protein between promyelocytic leukemia (PML) and RAR $\alpha(8,10)$. APL provides an excellent model in which a specific abnormal gene product is responsible for both the APL phenotype and for the in vitro and in vivo sensitivity to cell differentiation mediated by ATRA. The PML/RAR $\alpha$ protein retains most of the putative functional domains of the PML protein and the DNA- and ligand-binding domains of RAR $\alpha$. PML/RAR $\alpha$ can heterodimerize with RXR and 
PML $(11,12)$ and has the potential to interfere with the endogenous signaling pathways of both PML and RAR $\alpha$, thereby inhibiting terminal differentiation of hematopoietic precursor cell lines and promoting cell growth by blocking apoptotic cell death.

The members of the CCAAT/enhancer binding protein (C/EBP) family are implicated in the differentiation processes of a variety of mammalian cells including adipocytes, hepatocytes, and myeloid cells $(13,14)$. Some myeloid progenitors have high levels of $\mathrm{C} / \mathrm{EBP} \alpha$ that decrease during granulocytic differentiation; the levels of $\mathrm{C} / \mathrm{EBP} \beta$ and $-\delta$ are low in early myeloid stem cells and increase during granulocytic differentiation (14). Mice with genetic disruption of C/EBP genes confirm the importance of these proteins in myelopoiesis. C/EBP $\alpha$ knockout mice lack committed myeloid cells (15). These C/EBPs, together with other factors such as c-Myb, AML1, or PU.1, can induce the expression of myeloidspecific target genes (16-20).

The newly cloned human C/EBP $\varepsilon$ is a nuclear transcription factor expressed almost exclusively in myeloid cells (21-25). ATRA strongly upregulates C/EBPE expression in parallel with induction of granulocytic differentiation. Previously, we demonstrated that ATRA induced expression of C/EBPE by increasing the rate of transcription of the gene in the absence of new protein synthesis (22). Further studies showed that mice with genetic deletion of C/EBPE had a block in myeloid differentiation (26). This study attempts to elucidate the pathways involved in the regulation of the C/EBPE gene by PML/RAR $\alpha$ and RAR $\alpha$. In addition, to determine whether induction of C/EBPE expression in myeloid leukemia can mediate downstream granulocytic differentiation, we used U937 cells that have been stably transfected with C/EBPE under the control of a zinc-inducible promoter. We show that the induction of $\mathrm{C} / \mathrm{EBP} \varepsilon$ expression alone can induce granulocytic morphologic changes and granulocytic differentiation markers, as well as induce expression of secondary granule proteins characteristic of granulocytic differentiation.

\section{Methods}

Cell lines. NB4 cells (27) and UF-1 cells (28) were a kind gift from M. Lanotte (St. Louis Hospital, Paris, France) and M. Kizaki (Keio University, Tokyo, Japan), respectively. U937PR9 (29) and U937B412 (30) cells were generously provided by P.G. Pelicci (Perugia University, Perugia, Italy) and M. Ruthardt (University of Frankfurt, Frankfurt, Germany), respectively. RA-resistant subclones of NB4 cells (MR6, R4) were developed as described previously (31). Additional cell lines were either established by our group (KG-1) (32) or obtained from American Type Culture Collection (Rockville, Maryland, USA).

Cell differentiation and cell phenotype analysis. Cells were cultured with various differentiation inducers at concentrations as noted in the figure legends. Retinoids used in this study include ATRA (Sigma Chemical Co., St. Louis, Missouri, USA); 9-cis RA; and receptor-specific ligands AM580 (RAR $\alpha)$, SR11346 (RAR $\beta)$, SR11262 (RAR $\beta$ ), SR11254 (RAR $\gamma$ ), SR11248 (RAR $\gamma$ ), and SR11246 (RXR), as well as SR11283 (anti-AP-1) and SR11256 (panagonist) (gifts of M. Dawson; SRI International, Menlo Park, California, USA). U937PR9 and U937B412 cells were cultured either with or without $100 \mu \mathrm{M} \mathrm{ZnSO}_{4}$ for induction of either PML/RAR $\alpha$ or promyelocytic leukemia zinc finger/RAR $\alpha$ (PLZF/RAR $\alpha$ ) expression, respectively, in addi- tion to ATRA, as indicated in the figure legends. Differentiation was assessed by measuring CD11b and/or CD66b expressions using phycoerythrin-conjugated monoclonal antibodies and FACS ${ }^{\circledR}$, as described previously (22).

Plasmids. The chloramphenicol acetyl transferase (CAT) reporter constructs containing putative RARE from C/EBPE promoter/enhancer region ( $\mathrm{RARE}^{\mathrm{C} / \mathrm{EBPE}}$ ) were constructed. Either 2 or 3 copies of the wild-type or mutant (mut) oligonucleotides in tandem repeats were made double stranded by selfannealing and cloned into the SalI site of PBLCAT2 (PRE) (33) upstream of the enhancerless tk promoter of herpes simplex virus $\left(\right.$ RARE $_{\mathrm{n}}-t k-C A T$ or mut-RARE $\mathrm{n}_{\mathrm{n}}-t k-\mathrm{CAT}$ ) (see Figure $2 \mathrm{a}$ ). The CAT reporter constructs (either with or without the minimal th promoter) that contain $0.5 \mathrm{~kb}$ of C/EBPE upstream of the transcription start site (p0.5-tk-CAT, p0.5-CAT) were also constructed similarly. Mutant promoter reporter plasmids (mut-p0.5-tk-CAT, mut-p0.5-CAT) containing the same nucleotide changes as mut-RARE ${ }^{\mathrm{C} / \mathrm{EBPE}}$ were constructed using site-directed mutagenesis as described previously (34). Cytomegalovirus-driven expression plasmids pCMX-RAR $\alpha$, pCMX-RAR $\alpha 403$, and PCMX-PML/RAR $\alpha(9,35)$, and PCMX empty vector were kindly provided by R.M. Evans (The Salk Institute, San Diego, California, USA). A CAT reporter construct that does not contain a putative RARE site (PRE) was used as a negative control. Glutathione $S$-transferase (GST) fusion plasmids PGEX-RAR $\alpha$ and PGEX-RXR $\alpha$ (36) were gifts from C.K. Glass (University of California-San Diego, La Jolla, California, USA). The zinc-inducible C/EBPE expression vector

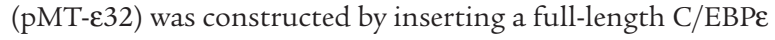
cDNA (pe32) at the XhoI and HindIII sites of MTCB6 ${ }^{+}$(pMT) (kind gift from F.J. Rauscher, III, The Wistar Institute, Philadelphia, Pennsylvania, USA) (37).

Development of U937-pMTE32 cells. A total of $2.5 \times 10^{7}$ U937 cells were electroporated in ElectroSquarePorator T820 (BTX, San Diego, California, USA) with $40 \mu \mathrm{g}$ of either PMTE32 or empty vector (pMT) and $10 \mu \mathrm{g}$ of pEGFP plasmid (CLONTECH Laboratories Inc., Palo Alto, California, USA) at $320 \mathrm{~V}$ for 30 milliseconds. Both pMTe32 and pMT, as well as pEGFP plasmids, contained neomycin resistance gene as a selectable marker. Selection for stably transfected cells was started 48 hours after the electroporation with G418 at $900 \mu \mathrm{g} / \mathrm{mL}$. In addition, 10 days after starting the G418 selection, bright green fluorescence-positive cells were sorted by FACS ${ }^{\circledR}$ and further cultured for expansion under continuous G418 selection. Multiple polyclonal cultures (>98\% GFP positive) were screened for zinc $(100 \mu \mathrm{M})$-inducible $\mathrm{C} / \mathrm{EBP \varepsilon}$ overexpression by Western blot analysis.

Western and Northern blot analyses. C/EBPE protein expression was detected by Western blot analysis using total cell lysates $(30 \mu \mathrm{g}$ protein) and purified rabbit polyclonal anti-C/EBPE antibody (18 $\mu \mathrm{g} / \mathrm{mL})$ as described previously $(23,24)$. Total cell lysates from COS-1 cells transiently transfected with either human C/EBPE cDNA expression plasmid (23) or empty vector were used in parallel as positive and negative controls, respectively. To ensure equal loading of cell lysates, either selected protein gels were stained or the transfer membranes were stripped and reprobed with actin antibody (Oncogene, Cambridge, Massachusetts, USA). Total RNA was extracted using Trizol (GIBCO BRL, Gaithersburg, Maryland, USA) according to the manufacturer's instructions, transferred onto nylon membrane, and hybridized with $3 \times 10^{6}$ $\mathrm{cpm} / \mathrm{mL}$ of the full-length C/EBPE or human neutrophil lactoferrin (a gift from N. Berliner, Yale University, New Haven, Connecticut, USA) cDNA probe as described previously (22).

Transfection and CAT assays. Transfections used $10 \mu \mathrm{g}$ of reporter plasmids and $5 \mu \mathrm{g}$ of expression plasmids in COS-1 cells using Lipofectin (GIBCO BRL). Sixteen hours after the addition of DNA, cells were incubated for an additional 48 hours in the medium containing $10 \%$ charcoal-stripped FCS either with or without ATRA $(1 \mu \mathrm{M})$ at $37^{\circ} \mathrm{C}, 5 \% \mathrm{CO}_{2}$, and CAT assays were performed using 
standard methods (38). CAT activity was quantified after autoradiography using the Ambis Radioisotopic Imager (CSP Inc., Billerica, Massachusetts, USA). Similarly, transfections were also carried out in the myeloid leukemia cell lines U937 and KCL22 by electroporation using the Gene Pulser electroporation apparatus (Bio-Rad Laboratories Inc., Hercules, California, USA). To correct for variations in transfection efficiency, cells were cotransfected with either RSV-luciferase or pSV- $\beta$ gal reporter plasmid, and either light production or $\beta$ gal activity was measured, respectively. At least 3 independent experiments were performed, and the mean fold induction and SE were calculated.

DNA binding and electrophoretic mobility shift assays. GST-RAR $\alpha$ and GST-RXR $\alpha$ fusion proteins were expressed in Escherichia coli and purified by binding to glutathione-Sepharose according to the manufacturer's instructions (Pharmacia Biotech, Piscataway, New Jersey, USA). Double-stranded oligonucleotides of the RARE sequences that are found upstream of C/EBPE $\left(\mathrm{RARE}^{\mathrm{C} / \mathrm{EBP \varepsilon}}\right)$ were labeled with $\left[\gamma^{-32} \mathrm{P}\right] \mathrm{ATP}$ (Du Pont NEN Research Products, Boston, Massachusetts, USA) using polynucleotide kinase (GIBCO BRL). Equal amounts of GST fusion proteins RAR $\alpha$ and RXR $\alpha$ were incubated with $1 \mathrm{ng}(50,000 \mathrm{cpm})$ of radiolabeled, double-stranded DNA probe as described previously (38). Increasing amounts of either wild-type or mutant unlabeled oligonucleotides were used for competition. DNA-protein complexes were resolved by electrophoresis through $4 \%$ polyacrylamide gels, and the gel was subsequently dried and autoradiographed with an intensifying screen at $-80^{\circ} \mathrm{C}(38)$.

Cell proliferation, morphology, and apoptosis assay. U937-pMT and U937-pMTE32 cells $\left(10^{4}\right)$ were grown in triplicate cultures in media either with or without $\mathrm{ZnSO}_{4}(100 \mu \mathrm{M})$, and mean viable cells were counted at days $0,2,5,7,9,12$, and 14 after trypan blue exclusion. Three independent experiments were performed, and the mean values with SE are reported graphically, with $P$ values determined at days $10-15$ by Student's $t$ test (confidence interval, 95\%). For morphologic examination, cytospin slide preparations of the cells were stained with Wright-Giemsa stain and examined under light microscopy. Apoptosis was measured by flow cytometry after reactions with phycoerythrin-conjugated Annexin V (PharMingen, San Diego, California, USA) and 7-amino-actinomycin (7-AAD) according to manufacturer's protocol at culture days $0,1,4$, and 10 with or without $\mathrm{ZnSO}_{4}$ in triplicate experiments. Annexin $\mathrm{V}$-positive and vital dye-negative cells were counted as apoptotic cells.

RT-PCR. RT-PCR for neutrophil secondary granule proteins, human neutrophil lactoferrin and neutrophil collagenase, was performed using standard methods as described previously (24). All PCR products were electrophoresed on a $1.5 \%$ agarose gel and transferred to a nylon membrane by alkaline transfer. Hybridization of the membranes was carried out using $\left[\gamma^{-32} \mathrm{P}\right]$ ATP endlabeled internal oligonucleotide probes to confirm specificity of the PCR product. PCR primer and internal oligonucleotide probe sequences and PCR conditions will be provided when requested. Each experiment included normal human neutrophil cDNA as a positive control, and the entire experiment was repeated at least 3 times using RNA samples made independently from separate cultures.

\section{Results}

Retinoid-induced expression of C/EBPE in myeloid cells is mediated by RAR $\alpha$. The RARs, especially RAR $\alpha$, are expressed in most hematopoietic cell lineages and their respective cell lines (39). Levels of RAR $\alpha$ expression in the APL cell line known as NB4 were not significantly regulated by exposure to retinoids (31). NB4 cells were incubated with various RAR $\alpha$-, RAR $\beta$-, RAR $\gamma$-, and RXR-selective analogues $\left(5 \times 10^{-7} \mathrm{M}\right.$ for 3 days $)$, including panagonists such as 9-cis RA and SR11256, as well as analogues selective for RAR $\alpha$ (AM580), RAR $\beta$ (SR11346, SR11262), RAR $\gamma$ (SR11254, SR11248), RAR (ATRA), and RXR (SR11246), and one with anti-AP-1 activity (SR11283). Expression of C/EBPE protein was most strongly upregulated by ATRA and 9-cis RA (Figure 1a). Ligands for $\mathrm{RAR} \alpha$ had the strongest effect on C/EBPE induction (Figure 1, a and b). Slight increases in C/EBPE mRNA expression were observed when NB4 cells were cultured with a RAR $\beta$-selective ligand (Figure 1b). The RAR $\gamma$ selective ligands, RXR-selective ligand, and anti-AP-1 ligand had no effect on the induction of C/EBPE expression (Figure 1, a and b).

Retinoid upregulation of C/EBPE promoter/enhancer activity through a putative RARE. To examine further the retinoiddependent transcriptional activation of C/EBPE through $\mathrm{RAR} \alpha, 0.5 \mathrm{~kb}$ of the C/EBPE promoter/enhancer region

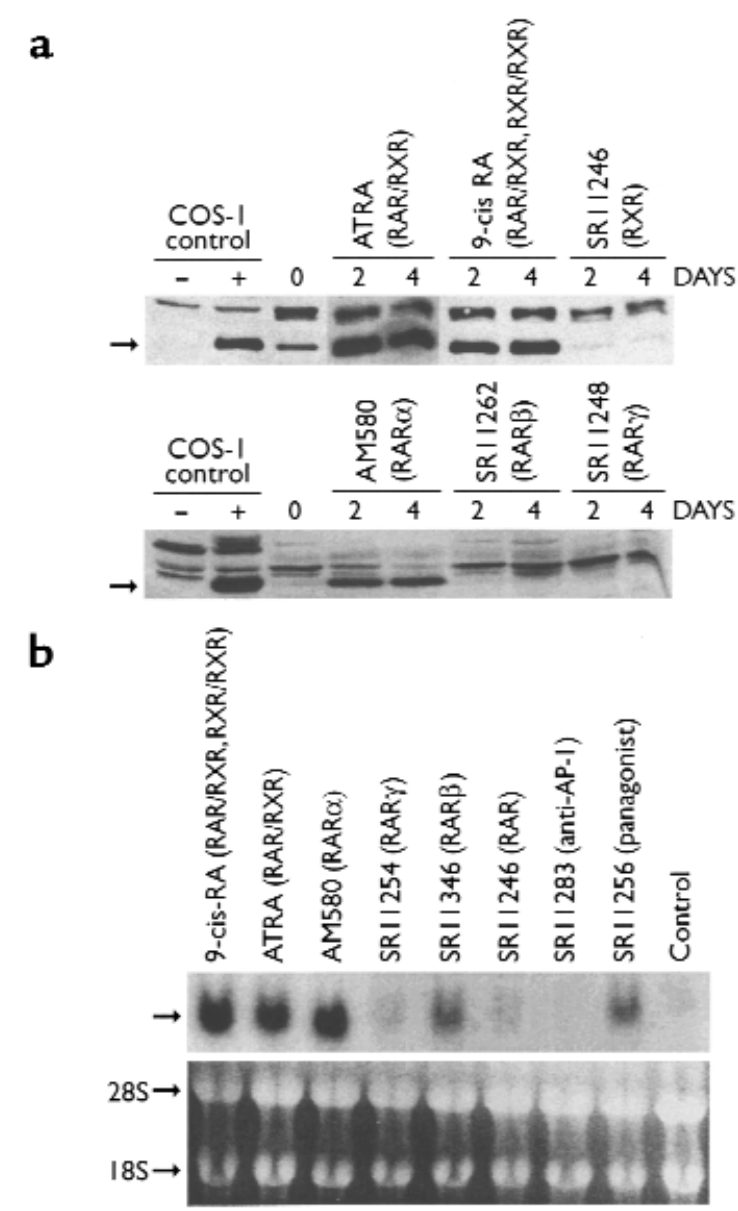

Figure 1

Induction of C/EBPE expression by retinoid receptor-selective ligands in NB4 cells. NB4 cells were incubated with retinoid receptor-selective ligands $\left(5 \times 10^{-7} \mathrm{M}\right)$ and harvested for total RNA or total cell lysates. $(\mathbf{a})$ Western blot analysis of C/EBPE. NB4 cells were harvested after 2 and 4 days of induction of differentiation. COS-1 cells transfected with either C/EBPE expression vector or empty vector were used as positive $(+)$ and negative (-) controls. Arrows denote C/EBPE. (b) Northern blot analysis for C/EBPE mRNA by hybridization with full-length C/EBPE cDNA probe. The top panel shows the C/EBPE mRNA of $1.2 \mathrm{~kb}$, and the bottom panel shows the ethidium bromide-stained $28 \mathrm{~S}$ and $18 \mathrm{~S}$ bands to confirm equivalent loading of RNA. 


\section{Figure 2}

Transactivational abilities of C/EBPE promoter/enhancer. (a) Schema of CAT reporter constructs with putative retinoic acid response element from C/EBPE (RARE ${ }^{C / E B P \varepsilon}$ ), mutant RAREC/EBPE , 0.5-kb C/EBPE promoter/enhancer region, and mutant $0.5-\mathrm{kb}$ C/EBPE promoter/enhancer region. (b) Retinoid-induced transactivation of C/EBPE promoter/enhancer in COS-1 cells. The transactivation of C/EBPE promoter/enhancer CAT reporters by RAR $\alpha$, mutant RAR $\alpha$ (RAR $\alpha 403$ ), and PML/RAR $\alpha$ were compared in either the presence (hatched bars) or absence (solid bars) of ATRA $\left(10^{-6} \mathrm{M}\right)$. The -fold induction of transactivation is calculated relative to that of PCMX transfected without ATRA treatment. (c) Retinoid-dependent transactivation of C/EBPE promoter/enhancer in the myeloid leukemia cell line KCL22. (d) Retinoid-dependent transcriptional activation of RARE ${ }^{C / E B P \varepsilon}$ - $t k$-CAT (CAT reporter containing 3 copies of putative RARE found in C/EBPE promoter/enhancer region in tandem repeats upstream of a minimal tk promoter) in COS-1 cells. (e) Lack of retinoiddependent transcriptional activation by mut-p0.5tk-CAT in COS- 1 cells. (f) DNA binding and EMSA of the RAR/RXR to RAREC/EBPE. The ${ }^{32}$ P-labeled RAREC/EBPE oligonucleotide was used as a probe for DNA binding and EMSA with a GST-RAR, GST-RXR, or GST control. For competition, either unlabeled wild-type or mutant RARE $/$ EBPE oligonucleotides in increasing amounts (1-, 10-, or 100-fold excess) were used in the binding reaction with the ${ }^{32} \mathrm{P}$-radiolabeled RARE ${ }^{\mathrm{C} / \mathrm{EBP}}$ and RAR/RXR heterodimer. Bands a and $b$ represent either RAR/RAR homodimers or RAR/RXR heterodimers bound to RAREC/EBPE oligonucleotide probe. Band $\mathrm{c}$ represents unbound probe. a

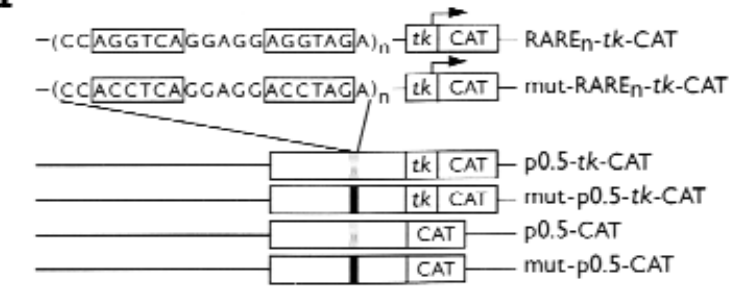

b PRE

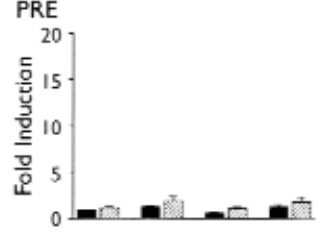

p0.5-tk-CAT

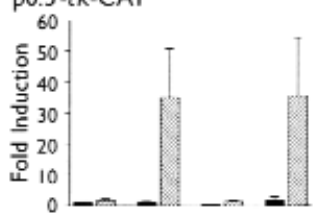

d RARE3-tk-CAT

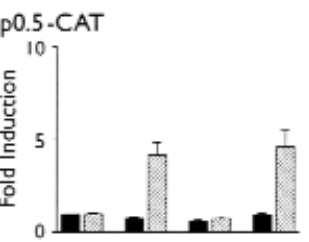

e mut-p0.5-tk-CAT
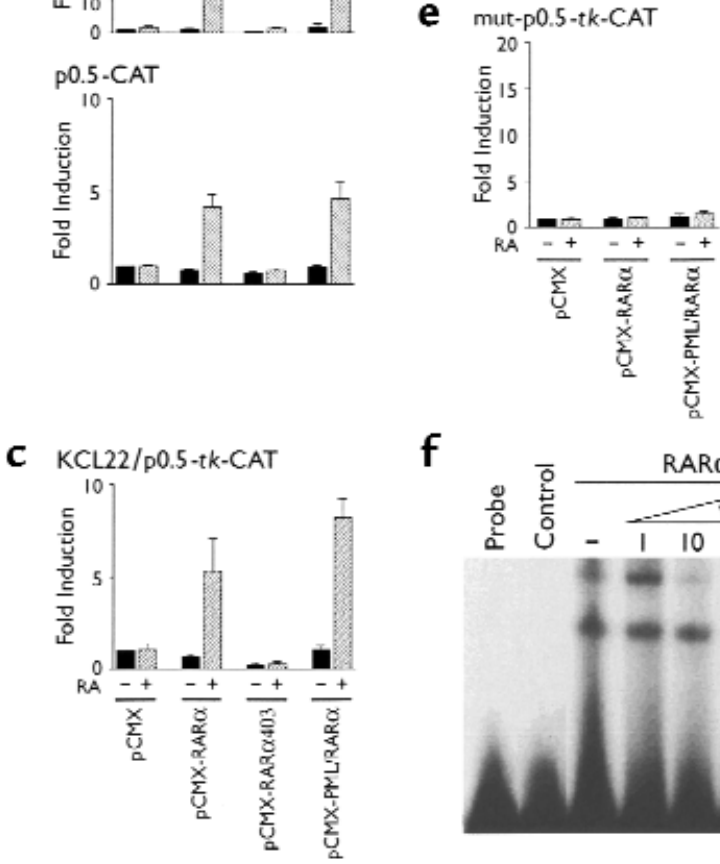

f
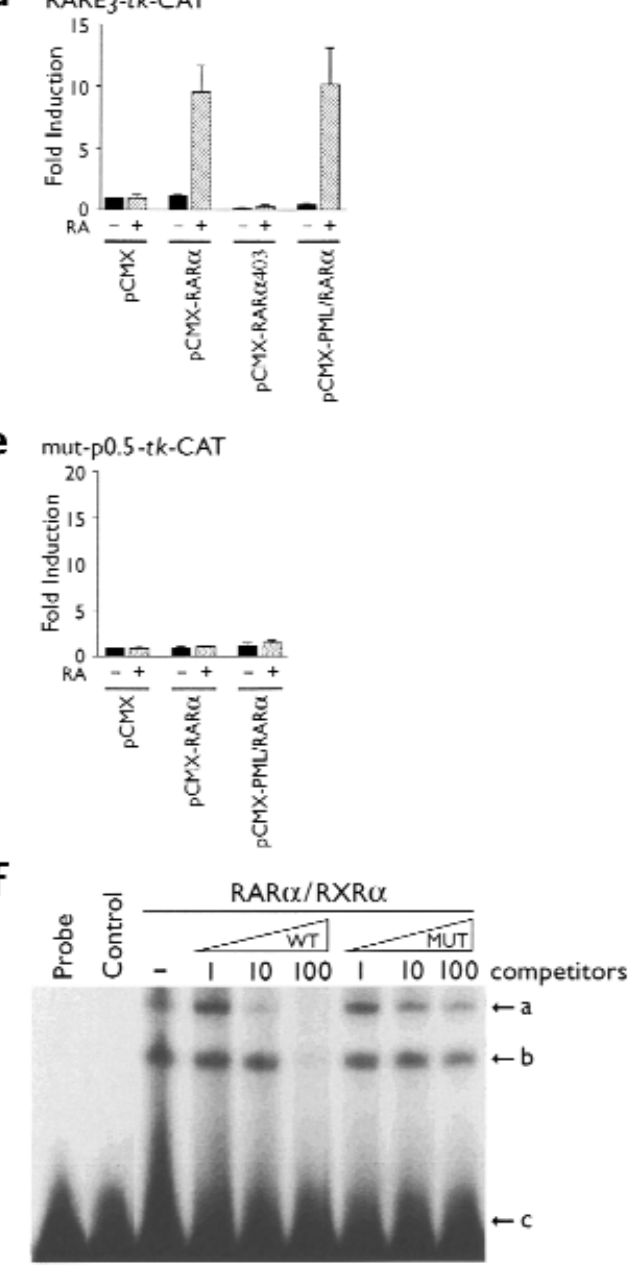

was subcloned into a CAT reporter construct either with or without the minimal tk promoter (p0.5-tk-CAT, p0.5CAT) (Figure 2a). PRE, an empty CAT reporter plasmid with the minimal tk promoter, was used as a control. The retinoid receptor expression vectors PCMX-RAR $\alpha$ (wildtype RAR $\alpha$ expression vector), PCMX-RAR $\alpha 403$ (dominant-negative mutant RAR $\alpha$ expression vector), and PCMX-PML/RAR $\alpha$ (PML/RAR $\alpha$ expression vector) or pCMX (empty vector) were cotransfected with either $\mathrm{C} / \mathrm{EBP} \varepsilon$ promoter/enhancer CAT reporter plasmids or PRE into COS- 1 cells. Cotransfection of PRE and expression vectors displayed a minimal level of transactivation without any response to RA (Figure $2 \mathrm{~b}$ ). Neither the wildtype RAR $\alpha$ nor fusion protein PML/RAR $\alpha$ displayed constitutive transactivation of $0.5-\mathrm{kb} \mathrm{C} / \mathrm{EBP} \varepsilon$ promoter/enhancer reporter constructs. However, in the presence of ATRA $\left(10^{-6} \mathrm{M}\right)$, both RAR $\alpha$ and PML/RAR $\alpha$ constructs could equally transactivate the C/EBPE promot- er/enhancer CAT reporter plasmids (Figure 2b), suggesting the presence of a functional RARE within the C/EBPE upstream construct. As expected, the cotransfection of either the empty expression vector ( $\mathrm{PCMX}$ ) or the dominant-negative receptor RAR $\alpha 403$ construct (pCMXRAR $\alpha 403$ ) with the reporter containing the upstream sequences of C/EBPE showed no ATRA-induced transactivation (Figure $2 \mathrm{~b}$ ). Both constructs with and without tk were studied because initial studies with the $5.2-\mathrm{kb}$ $\mathrm{C} / \mathrm{EBP \varepsilon}$ promoter/enhancer reporter construct without the minimal tk promoter did not show transactivation in either the presence or absence of ATRA (data not shown). In contrast, in the presence of minimal tk promoter, the 5.2-kb construct showed RA-dependent transactivation (data not shown). This suggests that the $5.2-\mathrm{kb}$ promoter/enhancer region may contain repressors of C/EBPE transcription that are located at greater than $500 \mathrm{bp}$ upstream of the start of transcription. 
To explore the potential cell type-specific transcriptional activity, similar experiments were performed in the myeloid leukemia cell lines U937 and KCL22. In both cell lines, ATRA-induced transactivation was observed with the p0.5-tk-CAT by both RAR $\alpha$ and PML/RAR $\alpha$ (Figure $2 \mathrm{c}$ and data not shown).

Because of these results, the 500-bp C/EBPE promoter/enhancer region was sequenced, and we discovered a potential RARE that was 190 bp upstream of the translation start site (23). This potential RARE consisted of 2 half-sites, AGGTCA and AGGTAG, separated by the expected 5 nucleotides. To show that the ATRA-responsive transactivation of the C/EBPE promoter/enhancer occurs via this RARE, either 2 or 3 copies of the wild-type oligonucleotide or mutant (mut) oligonucleotide in tandem repeats were inserted upstream of the enhancerless tk promoter and CAT reporter $\left(\mathrm{RARE}_{\mathrm{n}}-t k-\mathrm{CAT}\right.$ or mutRARE $_{n}$-tk-CAT) (Figure 2a). As expected, RARE F $_{3}-t k$-CAT showed a 10 -fold transactivation by both RAR $\alpha$ and PML/RAR $\alpha$, whereas mutations in the 2 half-sites abolished the ATRA-induced increase in reporter activity (Figure $2 \mathrm{~d}$ and data not shown), suggesting that this $\mathrm{RARE}^{\mathrm{C} / \mathrm{EBP}}$ is primarily responsible for the upregulation of C/EBPE observed in response to ATRA. These results were confirmed when the same mutation was made in the $0.5-\mathrm{kb}$ promoter reporter constructs (Figure 2, a and e; and data not shown).

In agreement with our hypothesis, electrophoretic mobility shift assays (EMSAs) showed that RAR/RXR heterodimers expressed in E. coli bound to RARE ${ }^{\mathrm{C} / \mathrm{EBP}}$ in vitro (Figure $2 \mathrm{f}$ ). The binding was competitively inhibited by unlabeled wild-type RARE ${ }^{\mathrm{C} / \mathrm{EBP} \varepsilon}$ oligonucleotides, but unlabeled mut-RAREC/EBPE oligonucleotides poorly competed, thereby confirming that RAR/RXR binds specifically to RAREC/EBPE.

Expression of PML/RAR $\alpha$ in the myeloid leukemia cell line U937 strongly enhances ATRA-induced C/EBPE expression. To explore further the role of the PML/RAR $\alpha$ fusion protein in the induction of C/EBPE expression, we used U937PR9 and U937B412 cells generated by stable transfection of the zinc-inducible MTPR plasmid containing the PML/RAR $\alpha$ cDNA (29) and PLZF/RAR $\alpha$ cDNA (30), respectively. U937PR9 cells express significantly higher induced levels of PML/RAR $\alpha$ than endogenous RAR $\alpha$, similar to those observed in fresh APL blasts $(29,40)$. Induction of expression of PML/RAR $\alpha$ by exposure of the cells to $\mathrm{ZnSO}_{4}$ in the absence of ATRA abolished the endogenous expression of C/EBPE (Figure 3, a and b). ATRA time response studies revealed that the induction of the PML/RAR $\alpha$ protein enhanced accumulation of the C/EBPE mRNA (30-fold at 48 hours) (Figure 3a). In contrast, without the induction of PML/RAR $\alpha$ protein, only a slight increase (<2-fold) in C/EBPE mRNA expression was observed (Figure 3a). ATRA dose response studies with the U937PR9 cells demonstrated a 25-fold induction of C/EBPE at $10^{-8} \mathrm{M}$ ATRA in the presence of $\mathrm{PML} / \mathrm{RAR} \alpha$, compared with a maximum of 2- to 3-fold induction without PML/RAR $\alpha$ (Figure 3b). The PLZF/RAR $\alpha$ fusion protein has been shown to cause morphologically indistinguishable APL, but these cells do not differentiate in the presence of ATRA (41). Induction of PLZF/RAR $\alpha$ expression in U937B412 cells by
$\mathrm{ZnSO}_{4}(100 \mu \mathrm{M})$ neither enhanced C/EBPE expression in response to ATRA nor suppressed expression of C/EBPE in the absence of retinoids (Figure 3c). The level of C/EBPE mRNA expression observed in U937B412 cells was similar to that seen in empty vector-transfected (U937-pMT) or untransfected U937 cells (Figure 3 and data not shown). These results suggest that the $\mathrm{C} / \mathrm{EBP} \varepsilon$ may be an important target gene of PML/RAR $\alpha$ in the presence of RA.

$C / E B P \varepsilon$ expression in retinoid-resistant APL cell lines. The role of C/EBPE expression in ATRA-resistant cell lines was explored. UF-1 cells, an APL cell line established from a patient resistant to ATRA, are also relatively resistant to ATRA in vitro (28). These cells were cultured for 3 days in various concentrations of ATRA and examined for the differentiation marker CD11b and expression of C/EBPE mRNA. Level of C/EBPE mRNA expression and differentiation did not occur until $\geq 10^{-6}$ M ATRA was added to the culture (Figure 4a). Also, no

\section{a}

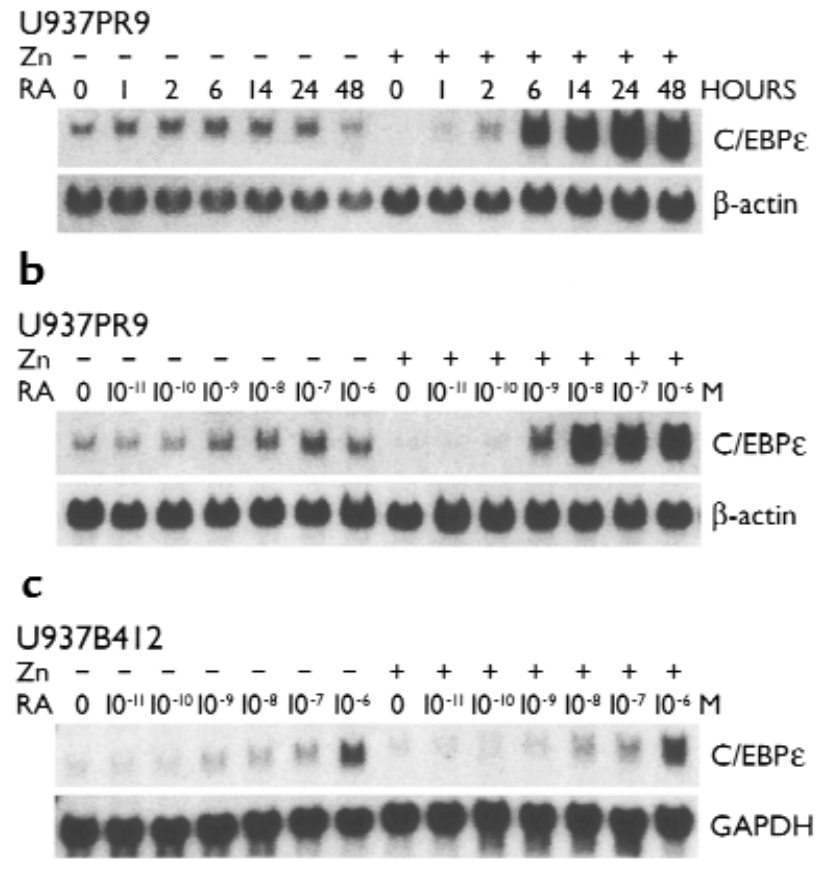

Figure 3

Marked increase in C/EBPE mRNA expression by ectopic expression of PML/RAR $\alpha$, but not PLZF/RAR $\alpha$, in U937 cells. U937PR9 or U937B412 cells, stably transfected with zinc-inducible PML/RAR $\alpha$ or PLZF/RAR $\alpha$ expression vectors, respectively, were cultured either with $(+)$ or without $(-)$ $100 \mu \mathrm{M} \mathrm{ZnSO}{ }_{4}$ with or without, ATRA and analyzed for induction of C/EBPE mRNA expression. (a) Time response by ATRA $\left(10^{-8} \mathrm{M}\right)$ in U937PR9 cells. Northern blot analysis was performed using $20 \mu \mathrm{g}$ of total RNA from U937PR9 cells exposed for various lengths of time to ATRA. (b) Dose response by ATRA in U937PR9 cells. Northern blot analysis was performed using $20 \mu \mathrm{g}$ of total RNA of U937PR9 cells exposed to various concentrations of ATRA for 24 hours. (c) Dose response by ATRA in U937B412 cells. Northern blot analysis was performed using $30 \mu \mathrm{g}$ of total RNA of U937B412 cells exposed to various concentrations of ATRA for 3 days. The top panels show the 1.2-kb C/EBPE transcript after hybridizations with fulllength $C / E B P \varepsilon$, and the bottom panels show the hybridizations with either $\beta$-actin or GAPDH probe to confirm equivalent RNA loading. 
a

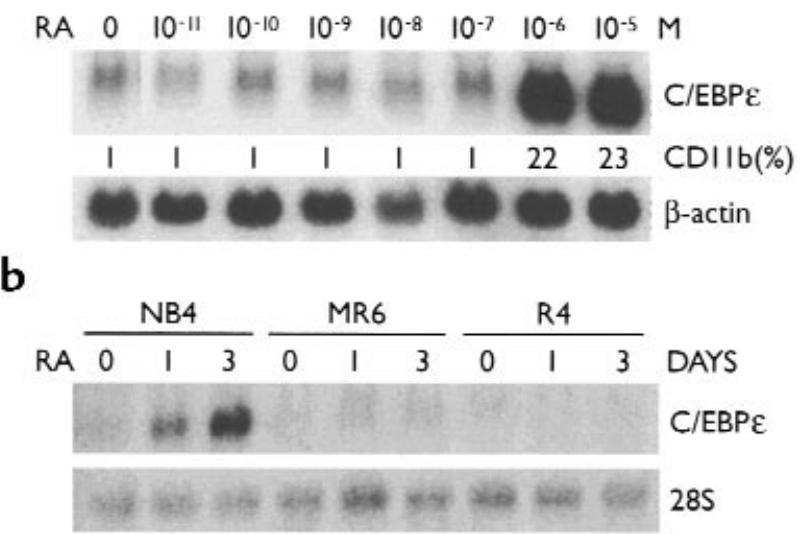

Figure 4

C/EBPE expression in retinoid-resistant APL cell lines. (a) Naturally occurring retinoid-resistant $A P L$ cell line UF-1 cells were cultured with increasing concentrations of ATRA for 3 days. Northern blot of total RNA (20 $\mu \mathrm{g}$ ) from UF-1 cells was hybridized with a C/EBPE cDNA probe (top) and a $\beta$-actin control (bottom). Differentiation was accessed by measuring CD11b expression using FACS ${ }^{\circledR}$. (b) Retinoid-resistant sublines of NB4: MR6 and R4. NB4 and retinoid-resistant sublines of NB4 cells were cultured either in the absence or presence of ATRA $\left(10^{-6} \mathrm{M}\right)$ and harvested at days 1 and 3. Northern blot analysis was performed using $5 \mu \mathrm{g}$ of total RNA. Top panel shows the C/EBPE mRNA (1.2 kb), and the bottom panel shows the $28 \mathrm{~S}$ bands to confirm equivalent loading of RNA.

induction of C/EBPE mRNA occurred when the completely RA-resistant subclones of NB4 cells, MR6 and R4 $(31,42)$, were cultured with ATRA $\left(10^{-6} \mathrm{M}\right)$ for 3 days (Figure 4b). These sublines of NB4 cells express $\mathrm{PML} / \mathrm{RAR} \alpha$ protein but have markedly decreased binding of ligand (31). Sequencing of PML/RAR $\alpha$ from R4 showed a point mutation in the ligand-binding domain of the fusion gene (42). Our data suggest that the differentiation capacity of APL cells by RA is closely linked to RA-dependent induction of C/EBPE expression.

Effect of C/EBPE overexpression in granulocytic differentiation of U937 cells. The U937 myelomonocytic leukemia cell line has the potential to differentiate toward either the monocytic or granulocytic lineages. To evaluate further whether induction of C/EBPE expression is a critical step in the commitment process to the granulocytic lineage, human $\mathrm{C} / \mathrm{EBP \varepsilon} \mathrm{cDNA}$ expression vector (pMTE32) under the control of a zinc-inducible metallothionein promoter was stably transfected into U937 cells (U937-pMTE32). When $\mathrm{ZnSO}_{4}(100 \mu \mathrm{M})$ was added to the media, C/EBPE protein expression increased dramatically in U937pMT\&32 cells (Figure 5a). U937-pMTE32 cells were cultured continuously in the presence of G418 $(900 \mu \mathrm{g} / \mathrm{mL})$ either with or without $\mathrm{ZnSO}_{4}(100 \mu \mathrm{M})$ for up to 22 days, and U937 cells, which were stably transfected with pMT control vector (U937-pMT), were cultured similarly. Changes in cell morphology were examined serially (Figure 5b). U937-pMTE32 cells grown without $\mathrm{ZnSO}_{4}$ and U937-pMT cells grown either with or without $\mathrm{ZnSO}_{4}$ had morphology that was indistinguishable from untransfected U937 cells (Figure 5b). These cells appear as myeloid leukemic blasts with uniformly large nuclei with high nuclear/cytoplasmic ratios, fine nuclear chromatin, multiple nucleoli, and scant blue cytoplasm. In contrast, when grown in the presence of $\mathrm{ZnSO}_{4}, \mathrm{U} 937-\mathrm{pMT \varepsilon} 32$ cells start to show morphologic features of differentiation as early as 4-5 days. These morphologic changes of differentiation progressed until some of the cells had the appearance of terminally differentiated neutrophils. These changes can be characterized by increase in cytoplasm, decrease in size of the nucleus, and more condensed nuclear chromatin, as well as appearance of band and polymorphonuclear forms. This level of differentiation peaked at days 10-12 of culture (Figure 5b).

Morphologic evidence of granulocytic differentiation correlated with increase in the expression of cell surface markers that are associated with myeloid differentiation (CD11b) and more terminal granulocytic differentiation (CD66b). CD11b expression increased from $4 \%$ to $5 \%$ in empty vector-transfected cells to $72 \%$ in U937-pMTE32 cells after 24 hours in the presence of zinc (Figure 5c). Expression of the terminally differentiated granulocyte marker CD66b was increased to $50 \%$ at day 4 and to $73 \%$ at day 10 of zinc incubation of the U937-pMTE32 cells (Figure 5d). This time-dependent increase of CD66b expression correlated with the morphologic changes of granulocytic differentiation.

Similarly, ectopic overexpression of C/EBPE in U937pMTE32 cells induced expression of human neutrophil lactoferrin and collagenase, which are secondary granule proteins specific for mature granulocytes, as shown by Southern blot analysis of RT-PCR products (Figure 5e). The induction of human neutrophil lactoferrin expression by overexpression of C/EBP $\varepsilon$ was also confirmed by Northern blot analysis (Figure 5f). Rate of cell proliferation was similar between U937-pMT and U937-pMTE32 either grown with or without $\mathrm{ZnSO}_{4}$ for the initial 4-5 days of culture. However, the proliferation rate of U937pMTE32 cells in zinc-containing media was significantly lower at days $10-15$ of culture $(P<0.001)$; thus, C/EBPE overexpression resulted in a decrease in cell proliferation consistent with terminal granulocytic differentiation (Figure $5 \mathrm{~g}$ ). In addition, ectopic expression of C/EBPE in U937 cells correlated with an increase in apoptosis at days 4 and 10 (Figure $5 \mathrm{~h}$ ). Up to $23 \%$ and $31 \%$ of cells were apoptotic at days 4 and 10, respectively, in U937-pMTe32 cells grown in zinc-containing media; in contrast, the level of apoptosis of U937-pMT cells either with or without zinc remained low: $9-10 \%$ at day 10 .

\section{Discussion}

A number of transcription factors including PU.1, AML$1, \mathrm{CBF} \beta, \mathrm{Myb}$, and $\mathrm{C} / \mathrm{EBP} \alpha$ are implicated in granulocytic differentiation of hematopoietic stem cells $(43,44)$. A new member of the C/EBP family, C/EBPE, joins this list of key myeloid transcription factors involved in granulopoiesis. Earlier studies demonstrated that expression of C/EBPE is restricted mainly to the myeloid lineage, and its increasing levels of expression parallel granulocytic differentiation (21-25). In addition, C/EBPE is transcriptionally upregulated by retinoids (22). The present data demonstrate that in APL, C/EBPE is a target gene for retinoids via the RAR $\alpha$ and PML/RAR $\alpha$ pathway, and its induction of expression is critical in granulocytic dif- 


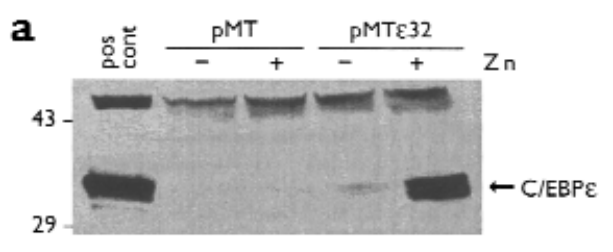

b

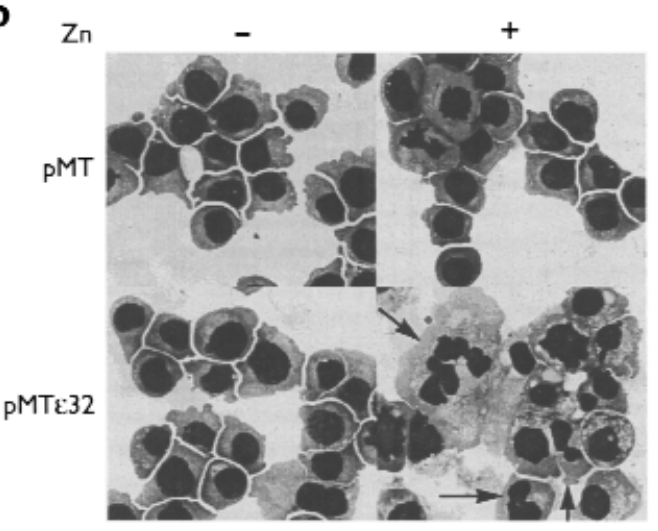

C

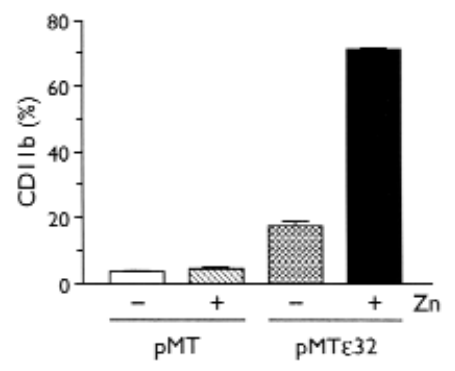

d

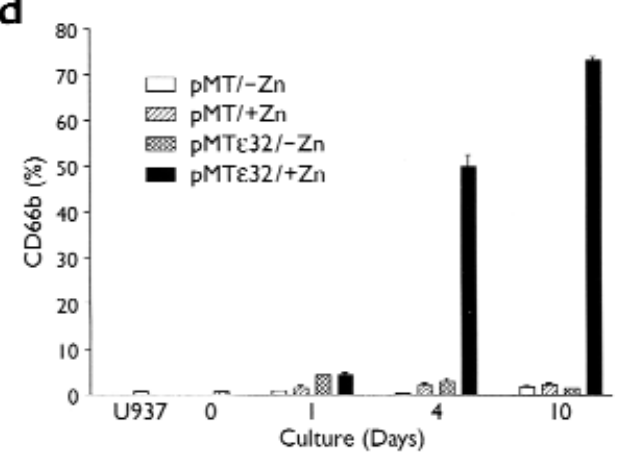

$\mathbf{e}$

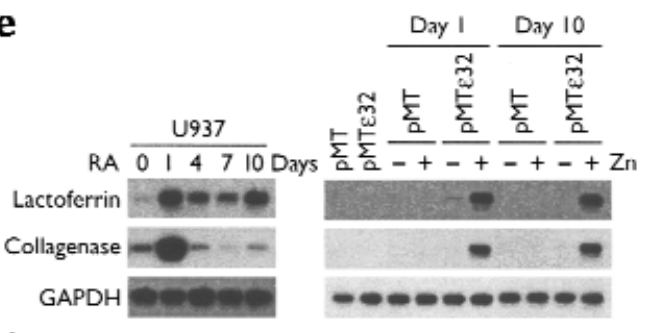

f

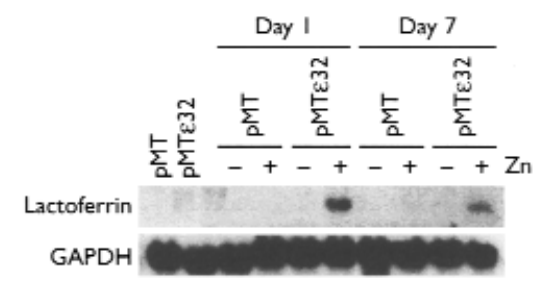

g

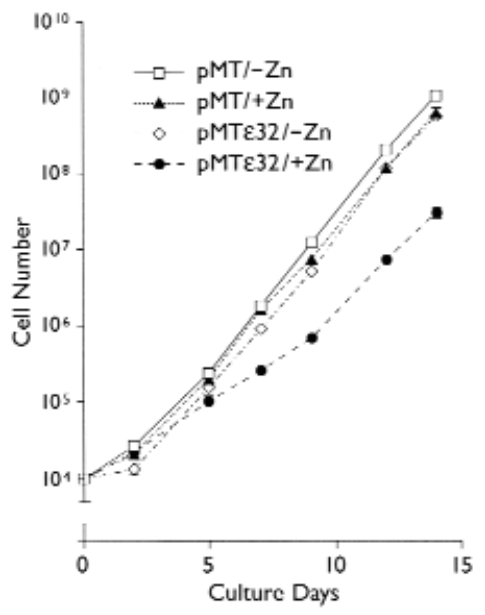

h

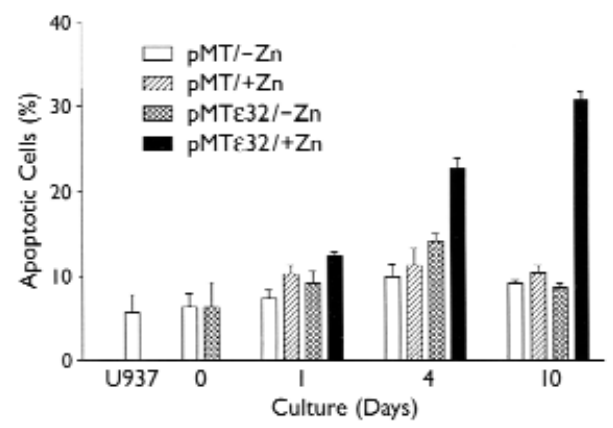

Figure 5

Effect of C/EBPE overexpression in U937 cells. (a) Western blot of U937 cells stably transfected with either empty vector or zinc-inducible C/EBPE expression vector. COS-1 cells transfected with C/EBPE expression vector were used as positive control. (b) C/EBPE overexpression induces granulocytic differentiation of $U 937$ cells. Shown are representative morphologic changes seen at 10 days of zinc incubation in Wright-Giemsa-stained cytospin slides under light microscopy. Arrows represent granulocytic differentiation. (c) CD11b expression increases with zinc induction (24 hours) of C/EBPE. (d) CD66b expression is strongly upregulated at days 4 and 10 of zinc incubation in U937-pMTE32 cells. (e) Secondary granule protein transcripts are induced with C/EBPE overexpression in U937 cells. Shown are representative Southern blots of RT-PCR products for human neutrophil lactoferrin and collagenase genes in either U937 cells incubated with ATRA (10-6 M for 1, 4, 7, and 10 days) or U937-pMT and U937-pMTE32 cells cultured either with or without $\mathrm{ZnSO}_{4}(100 \mu \mathrm{M})$. Southern blot of GAPDH RT-PCR product is shown as a control. (f) Induction of human neutrophil lactoferrin mRNA by C/EBPE

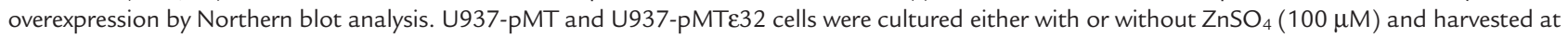
days 0,1 , and 7 of culture. (g) $1 \times 10^{4}$ U937-pMT and U937-pMTE32 cells were grown in media either with or without ZnSO 4 (100 $\mu$ M), and viable cells were counted at days $0,2,5,7,9,12$, and 14 after trypan blue exclusion to examine the rate of cell proliferation. Three independent experiments were performed, and the mean values with SE are reported graphically ( $P<0.001$ by Student's $t$ test at days $10-15)$. (h) C/EBPE-induced granulocytic differentiation parallels the increase in apoptosis. Each point in all the graphs represents the mean $( \pm$ SEM) from 3-4 independent experiments. 
ferentiation and may also be important in predicting retinoid responsiveness.

RAR $\alpha$ is frequently targeted by chromosomal translocations in the M3 form (APL) of acute myeloid leukemia. The chimeric PML/RAR $\alpha$ fusion protein resulting from $t(15 ; 17)$ has been implicated in the pathogenesis of APL. The APL cell line NB4, with the characteristic chromosome 15/17 translocation, can be induced to differentiate with retinoids. Unlike HL60, NB4 cells are resistant to other nonretinoid differentiation agents; however, the NB4 cells become sensitive to these nonretinoid agents if the cells are briefly pretreated with ATRA (45). The expression of C/EBPe in NB4 cells is markedly induced by retinoids and by nonretinoid granulocytic differentiation inducers, such as DMSO and HMBA, when these cells are initially primed by pulse exposure to ATRA. Increased expression of C/EBPE paralleled enhanced expression of myeloid differentiation markers (data not shown) (22). In contrast, without initial priming with ATRA, the nonretinoid inducers did not elevate expression of C/EBPE or produce granulocytic differentiation. This phenomenon of C/EBPE induction was not observed when NB4 cells were treated with arsenic trioxide $\left(\mathrm{As}_{2} \mathrm{O}_{3}\right)\left(10^{-8}\right.$ to $10^{-7} \mathrm{M}$, 1-4 days; data not shown), which has been reported to trigger a partial differentiation of the cells (46). In addition, KG1 (early myeloblastic leukemia cell line) and K562 (erythroleukemia cell line) did not show significant retinoid-dependent granulocytic differentiation, and these cells did not have a retinoid-dependent induction of C/EBPE expression (data not shown).

We have previously shown that the retinoid-dependent accumulation of C/EBPE mRNA was regulated at the transcriptional level and that this was probably a direct effect because blockade of new protein synthesis did not inhibit ATRA induction of C/EBPE mRNA in NB4 cells (22). In this study, using retinoids selective for different RAR and RXR isomers, we demonstrate that the increase in $\mathrm{C} / \mathrm{EBP} \varepsilon$ expression is mediated primarily through the RAR $\alpha$ pathway. RAR $\alpha$ is widely expressed in many hematopoietic cell types and cell lines, and RAR $\alpha$ mediates its biologic effects by interacting with specific DNA sequences (RARE) that regulate the expression of the associated gene. By analyzing the promoter/enhancer region of C/EBPE, we localized a potential RARE site. The nucleotide sequence of the putative RARE ${ }^{\mathrm{C} / \mathrm{EBP} \text {, }}$ AGGTCAGGAGGAGGTAG, is very similar to the core motif of known RAREs' (A/G)G(G/T)TCA. In addition, the 2 core motifs are separated by 5 nucleotides, which is the preferential spacer number for binding of RAR/RXR heterodimers. We demonstrated that the reporter plasmids containing RARE ${ }^{\mathrm{C} / \mathrm{EBP}}$ can be transactivated in the presence of ATRA. EMSA studies confirmed the specific binding of RAR/RXR heterodimers to RAREC/EBPE sequence. Reporter studies clearly demonstrated the retinoid responsiveness of the C/EBPE promoter.

Prior studies showed that U937 cells expressing PML/RAR $\alpha$ failed to differentiate terminally when cultured with $1,25(\mathrm{OH})_{2} \mathrm{D}_{3}$; however, in the presence of RA, these cells did differentiate, as shown by greater NBT positivity $(29,47)$. Using U937 cells stably transfected with a zinc-inducible PML/RAR $\alpha$ (U937PR9) or PLZF/RAR $\alpha$ (U937B412) expression plasmid, we addressed the ques- tion of whether these fusion proteins can promote retinoid-dependent $\mathrm{C} / \mathrm{EBP} \varepsilon$ expression. In the absence of RA added to the cultures, induction of PML/RAR $\alpha$ expression in U937PR9 cells suppressed the expression of $\mathrm{C} / \mathrm{EBP} \varepsilon$, whereas, in the presence of a therapeutic concentration of RA, PML/RAR $\alpha$ significantly increased the level of C/EBPE expression in a time- and dose-dependent manner (Figure 3, a and b). These results suggest, but do not prove, that the expression of PML/RAR $\alpha$ in myeloid cells blocks terminal myeloid differentiation by suppression of C/EBPE expression and enhances the development of a malignant clone. Our findings are also consistent with a study of C/EBPE knockout mice. These mice showed a block in their terminal granulocytic differentiation (26). Furthermore, our results with U937PR9 suggest that the block in terminal myeloid differentiation in APL cells is reversed by the marked enhancement of C/EBPE expression by PML/RAR $\alpha$ when a pharmacologic concentration of RA is present.

A small subset of patients with APL develop promyelocytic leukemia with chimeric PLZF/RAR $\alpha$ fusion protein resulting from $t(11 ; 17)(41,48)$. APL caused by $\mathrm{PLZF} / \mathrm{RAR} \alpha$ is morphologically indistinguishable from APL caused by PML/RAR $\alpha$ and is usually unresponsive to retinoids $(30,41)$. PLZF/RAR $\alpha$ has a retinoid-independent corepressor binding domain in the $\mathrm{NH}_{2}$-terminus (POZ domain) of PLZF, which may be the cause for retinoid resistance of these APL cells both in vivo and in vitro (49). Our study showed that the induction of PLZF/RAR $\alpha$ expression in U937B412 cells had no suppressive effect on C/EBPE expression (Figure 3c), suggesting that if a common pathway of pathogenesis for these 2 forms of APL does exist, it does not involve depressed expression of C/EBPE.

However, consistent with our hypothesis that induction of C/EBPE expression parallels responsiveness to retinoids, the U937B412 cells cultured with retinoids neither had an enhanced expression of C/EBPE nor underwent granulocytic differentiation. Our hypothesis was further solidified by studying RA-resistant APL cell lines. UF-1 is a recently developed APL cell line that is naturally RA resistant (28). At less than $10^{-6} \mathrm{M}$ ATRA, the level of C/EBPE expression was low and no differentiation was observed. In contrast, C/EBPE expression increased in response to a high concentration of ATRA $\left(\geq 10^{-6} \mathrm{M}\right)$, and concomitantly, a modest level of differentiation was observed as measured by CD11b positivity. We noted a similar but even more dramatic finding using NB4 sublines (MR6, R4). These cells were completely resistant to RA induction of both differentiation (31) and expression of C/EBPE. Abnormally functioning PML/RAR $\alpha$, as measured by alterations in ligand-binding ability and RA-induced gene expression, is the proposed mechanism for their RA resistance (31). The $\mathrm{PML} / \mathrm{RAR} \alpha$ in $\mathrm{R} 4$ was found to contain a mutation that causes the loss of ligand binding (42). Although RA induces the granulocytic differentiation of HL60 and U937 cells in vitro, the induction of C/EBPE expression is only modest compared with the APL cell line NB4. Thus, in each of the PML/RAR $\alpha$-containing cell lines, a close correlation exists between induction of differentiation and induction of C/EBPE expression. 
To strengthen further our hypothesis that $\mathrm{C} / \mathrm{EBP} \varepsilon$ is a critical downstream target gene in retinoid-induced granulocytic differentiation, we showed that ectopic overexpression of C/EBPE alone in a myeloid leukemia cell line (U937) can rapidly induce the changes that are consistent with terminal granulocytic differentiation. Morphologic changes were evident as early as 4-5 days of C/EBPE induction, and these changes paralleled the increase in CD11b and CD66b expression. CD66b (formerly CD67) is a granulocyte-specific activation antigen expressed in secondary granule membranes of neutrophilic and eosinophilic granulocytes at late stages of differentiation. Upon activation of granulocytes, the $\mathrm{CD} 66 \mathrm{~b}$ is rapidly upregulated. Neutrophil secondary granule protein expression is a hallmark of the crucial commitment step that is associated with the transition between the promyelocyte and myelocyte stages of normal granulocytic differentiation and loss of bilineage potential. Leukemia cell lines, including HL60, NB4, and U937 cells, do not express secondary granule proteins such as human neutrophil lactoferrin and neutrophil collagenase $(50,51)$. We have shown that ectopic overexpression of $\mathrm{C} / \mathrm{EBPE}$ alone can rapidly induce secondary granule protein transcripts in U937 cells. Induction of secondary granule protein transcripts by overexpression of C/EBPE was similar to RA induction of these transcripts in U937 cells.

A number of genes have been identified as being induced by RA (52-55). However, some of these are regulated as an indirect response to RA. Others appear to be regulated directly by RA, but their biologic function in the context of myeloid differentiation remains unclear. $\mathrm{C} / \mathrm{EBP \varepsilon}$ is a primary response gene of RA, which is directly induced via the RAR $\alpha$ and/or PML/RAR $\alpha$ pathway, and its expression is strongly associated with RAdependent granulocytic differentiation. These findings are consistent with the findings that C/EBPE knockout mice have a block in granulocytic differentiation (26), and are congruent with our hypothesis that induction of $\mathrm{C} / \mathrm{EBP} \varepsilon$ expression is critical in RA-dependent granulocytic differentiation. Furthermore, our data strongly suggest that $\mathrm{C} / \mathrm{EBP} \varepsilon$ may be an important target gene for RA in the treatment of APL and that the retinoid resistance that can develop in APL patients may be secondary to lack of induction of C/EBPE.

\section{Acknowledgments}

We thank all the investigators who generously shared their valuable reagents with us. We are grateful to Wenlin Shao for NB4-resistant cell line work and to Seiji Kawano for pMTE32 and helpful suggestions. We also thank Rasha Germain, Vong Huynh, Scott Kwok, Jennifer Le, and Agnes Silla for their excellent technical assistance. This work was supported by National Institutes of Health grants, the Parker Hughes Trust, and the C. and H. Koeffler Fund. H.P. Koeffler is a member of the University of California-Los Angeles Jonsson Comprehensive Cancer Center and holds an endowed Mark Goodson Chair of Oncology Research at Cedars-Sinai Medical Center.

1. Evans, R.M. 1988. The steroid and thyroid hormone receptor super family. Science. 240:889-895.

2. Leid, M., et al. 1992. Purification, cloning, and RXR identity of the HeLa cell factor with which RAR or TR heterodimerizes to bind target sequences efficiently. Cell. 68:377-395.

3. Kliewer, S.A., Umesono, K., Mangelsdorf, D.J., and Evans, R.M. 1992.
Retinoid X receptor interacts with nuclear receptors in retinoic acid, thyroid hormone and vitamin $\mathrm{D}_{3}$ signalling. Nature. 355:446-449.

4. Huang, M.E., et al. 1988. Use of all-trans retinoic acid in the treatment of acute promyelocytic leukemia. Blood. 72:567-572.

5. Warrell, R.P., Jr., et al. 1991. Differentiation therapy of acute promyelocytic leukemia with tretinoin (all-trans-retinoic acid). N. Engl. J. Med. 324:1385-1393.

6. Heyman, R.A., et al. 1992. 9-cis retinoic acid is a high affinity ligand for the retinoid $\mathrm{X}$ receptor. Cell. 68:397-406.

7. Levin, A.A., et al. 1992. 9-cis retinoic acid stereoisomer binds and activates the nuclear receptor RXR $\alpha$. Nature. 355:359-361.

8. de The, H., Chomienne, C., Lanotte, M., Degos, L., and Dejean, A. 1990. The $t(15 ; 17)$ translocation of acute promyelocytic leukaemia fuses the retinoic acid receptor $\alpha$ gene to a novel transcribed locus. Nature. 347:558-561.

9. Umesono, K., Murakami, K.K., Thompson, C.C., and Evans, R.M. 1991. Direct repeats as selective response elements for the thyroid hormone, retinoic acid, and vitamin $\mathrm{D}_{3}$ receptors. Cell. 65:1255-1266.

10. Goddard, A.D., Borrow, J., Freemont, P.S., and Solomon, E. 1991. Characterization of a zinc finger gene disrupted by the $t(15 ; 17)$ in acute promyelocytic leukemia. Science. 254:1371-1374.

11. Kastner, P., et al. 1992. Structure, localization and transcriptional properties of two classes of retinoic acid receptor alpha fusion proteins in acute promyelocytic leukemia (APL): structural similarities with a new family of oncoproteins. EMBO J. 11:629-642.

12. Perez, A., et al. 1993. PMLRAR homodimers: distinct DNA binding properties and heteromeric interactions with RXR. EMBO J. 12:3171-3182.

13. Birkenmeier, E.H., et al. 1989. Tissue-specific expression, developmental regulation, and genetic mapping of the gene encoding CCAAT/enhancer binding protein. Genes Dev. 3:1146-1156.

14. Scott, L.M., Civin, C.I., Rorth, P., and Friedman, A.D. 1992. A novel temporal expression pattern of three C/EBP family members in differentiating myelomonocytic cells. Blood. 80:1725-1735.

15. Zhang, D.E., et al. 1997. Absence of granulocyte colony-stimulating factor signaling and neutrophil development in CCAAT enhancer binding protein alpha-deficient mice. Proc. Natl. Acad. Sci. USA. 94:569-574.

16. Hohaus, S., et al. 1995. PU.1 (Spi-1) and C/EBP $\alpha$ regulate expression of the granulocyte-macrophage colony-stimulating factor receptor $\alpha$ gene. Mol. Cell. Biol. 15:5830-5845.

17. Ness, S.A., Kowenz-Leutz, E., Casini, T., Graf, T., and Leutz, A. 1993. Myb and NF-M: combinatorial activators of myeloid genes in heterologous cell types. Genes Dev. 7:749-759.

18. Oelgeschlager, M., Nuchprayoon, I., Luscher, B., and Friedman, A.D. 1996. C/EBP, c-Myb, and PU.1 cooperate to regulate the neutrophil elastase promoter. Mol. Cell. Biol. 16:4717-4725.

19. Smith, L.T., Hohaus, S., Gonzalez, D.A., Dziennis, S.E., and Tenen, D.G. 1996. PU.1 (Spi-1) and C/EBP $\alpha$ regulate the granulocyte colony-stimulating factor receptor promoter in myeloid cells. Blood. 88:1234-1247.

20. Zhang, D.E., et al. 1996. Function of PU.1 (Spi-1), C/EBP, and AML1 in early myelopoiesis: regulation of multiple myeloid CSF receptor promoters. Curr. Top. Microbiol. Immunol. 211:137-147.

21. Antonson, P., Stellan, B., Yamanaka, R., and Xanthopoulos, K.G. 1996. A novel human CCAAT/enhancer binding protein gene, $\mathrm{C} / \mathrm{EBP} \varepsilon$, is expressed in cells of lymphoid and myeloid lineages and is localized on chromosome $14 \mathrm{q} 11.2$ close to the T-cell receptor $\alpha / \delta$ locus. Genomics. 35:30-38.

22. Chih, D., Chumakov, A.M., Park, D.J., Silla, A.G., and Koeffler, H.P. 1997. Modulation of mRNA expression of a novel human myeloid-selective CCAAT/enhancer binding protein gene (C/EBPE). Blood. 90:2987-2994.

23. Chumakov, A.M., et al. 1997. Cloning of the novel human myeloidcell-specific C/EBPE transcription factor. Mol. Cell. Biol. 17:1375-1386.

24. Morosetti, R., et al. 1997. A novel, myeloid transcription factor, C/EBPE, is upregulated during granulocytic, but not monocytic, differentiation. Blood. 90:2591-2600.

25. Yamanaka, R., et al. 1997. CCAAT/enhancer binding protein $\varepsilon$ is preferentially up-regulated during granulocytic differentiation and its functional versatility is determined by alternative use of promoters and differential splicing. Proc. Natl. Acad. Sci. USA. 94:6462-6467.

26. Yamanaka, R., et al. 1998. Impaired granulopoiesis, myelodysplasia, and early lethality in CCAAT/enhancer binding protein $\varepsilon$-deficient mice. Proc. Natl. Acad. Sci. USA. 94:13187-13192.

27. Lanotte, M., et al. 1991. NB4, a maturation inducible cell line with $\mathrm{t}(15 ; 17)$ marker isolated from a human acute promyelocytic leukemia (M3). Blood. 77:1080-1086

28. Kizaki, M., et al. 1996. Establishment and characterization of a novel acute promyelocytic leukemia cell line (UF-1) with retinoic acid-resistant features. Blood. 88:1824-1833.

29. Grignani, F., et al. 1993. The acute promyelocytic leukemia-specific PML-RAR $\alpha$ fusion protein inhibits differentiation and promotes survival of myeloid precursor cells. Cell. 74:423-431.

30. Ruthardt, M., et al. 1997. Opposite effects of the acute promyelocytic leukemia PML-retinoic acid receptor $\alpha(\mathrm{RAR} \alpha)$ and PLZF-RAR $\alpha$ fusion 
proteins on retinoic acid signalling. Mol. Cell. Biol. 17:4859-4869.

31. Rosenauer, A., et al. 1996. Alterations in expression, binding to ligand and DNA, and transcriptional activity of rearranged and wild-type retinoid receptors in retinoid-resistant acute promyelocytic leukemia cell lines. Blood. 88:2671-2682.

32. Koeffler, H.P. and Golde, D.W. 1978. Acute myelogenous leukemia: a human cell line responsive to colony-stimulating activity. Science. 200:1153-1154.

33. Luckow, B. and Schutz, G. 1987. CAT constructions with multiple unique restriction sites for the functional analysis of eukaryotic promoters and regulatory elements. Nucleic Acids Res. 1:5490.

34. Ke, S.H., and Madison, E.L. 1997. Rapid and efficient site-directed mutagenesis by single-tube 'megaprimer' PCR method. Nucleic Acids Res. 25:3371-3372.

35. Kakizuka, A., et al. 1991. Chromosomal translocation $\mathrm{t}(15 ; 17)$ in human acute promyelocytic leukemia fuses RAR $\alpha$ with a novel putative transcription factor, PML. Cell. 66:663-674.

36. Kurokawa, R., et al. 1995. Polarity-specific activities of retinoic acid receptors determined by a co-repressor. Nature. 377:451-454

37. Cook, D.M., Hinkes, M.T., Bernfield, M., and Rauscher, F.J. 1996. Transcriptional activation of the syndecan-1 promoter by the Wilms' tumor protein WT1. Oncogene. 13:1789-1799.

38. Park, D.J., et al. 1994. Transactivational and DNA binding abilities of endogenous p53 in p53 mutant cell lines. Oncogene. 9:1899-1906.

39. de The, H., Marchio, A., Tiollais, P., and Dejean, A. 1989. Differential expression and ligand regulation of the retinoic acid receptor alpha and beta genes. EMBO J. 8:429-433.

40. Pandolfi, P.P., et al. 1992. Genomic variability and alternative splicing generate multiple PML/RAR $\alpha$ transcripts that encode aberrant PML proteins and PML/RAR $\alpha$ isoforms in acute promyelocytic leukaemia. EMBO J. 11:1397-1407.

41. Guidez, F., et al. 1994. Poor response to all-trans retinoic acid therapy in a t $(11 ; 17)$ PLZF/RAR $\alpha$ patient. Leukemia. 8:312-317.

42. Shao, W., Benedetti, L., Lamph, W.W., Nervi, C., and Miller, W.H., Jr. 1997. A retinoid-resistant acute promyelocytic leukemia subclone expresses a dominant negative PML-RAR $\alpha$ mutation. Blood. 89:4282-4289.

43. Shivdasani, R.A., and Orkin, S.H. 1996. The transcriptional control of hematopoiesis. Blood. 87:4025-4039.

44. Tenen, D.G., Hromas, R., Licht, J.D., and Zhang, D.E. 1997. Transcrip- tion factors, normal myeloid development, and leukemia. Blood. 90:489-519

45. Chen, A., et al. 1994. Retinoic acid is required for and potentiates differentiation of acute promyelocytic leukemia cells by nonretinoid agents. Blood. 84:2122-2129.

46. Chen, G.Q., et al. 1996. In vitro studies on cellular and molecular mechanisms of arsenic trioxide $\left(\mathrm{As}_{2} \mathrm{O}_{3}\right)$ in the treatment of acute promyelocytic leukemia: $\mathrm{As}_{2} \mathrm{O}_{3}$ induces NB4 cell apoptosis with downregulation of $\mathrm{Bcl}-2$ expression and modulation of PML-RAR $\alpha / \mathrm{PML}$ proteins. Blood. 88:1052-1061.

47. Testa, U., et al. 1994. PML/RAR $\alpha^{+}$U937 mutant and NB4 cell lines: retinoic acid restores the monocytic differentiation response to vitamin $\mathrm{D}_{3}$. Cancer Res. 54:4508-4515.

48. Licht, J.D., et al. 1995. Clinical and molecular characterization of a rare syndrome of acute promyelocytic leukemia associated with translocation (11;17). Blood. 85:1083-1094.

49. Hong, S.H., David, G., Wong, C.W., Dejean, A., and Privalsky, M.L. 1997. SMRT corepressor interacts with PLZF and with the PML-retinoic acid receptor $\alpha(\mathrm{RAR} \alpha)$ and PLZF-RAR $\alpha$ oncoproteins associated with acute promyelocytic leukemia. Proc. Natl. Acad. Sci. USA. 94:9028-9033.

50. Khanna-Gupta, A., Kolibaba, K., Zibello, T.A., and Berliner, N. 1994. NB4 cells show bilineage potential and an aberrant pattern of neutrophil secondary granule protein gene expression. Blood. 84:294-302.

51. Khanna-Gupta, A., Zibello, T., and Berliner, N. 1996. Coordinate regulation of neutrophil secondary granule protein gene expression. Curr. Top. Microbiol. Immunol. 211:165-171.

52. Drach, J., Zhao, S., Malavasi, F., and Mehta, K. 1993. Rapid induction of CD38 antigen on myeloid leukemia cells by all trans-retinoic acid. Biochem. Biophys. Res. Commun. 195:545-550.

53. Fraij, B.M., Birckbichler, P.J., Patterson, M.K.J., Lee, K.N., and Gonzales, R.A. 1992. A retinoic acid-inducible mRNA from human erythroleukemia cells encodes a novel tissue transglutaminase homologue. J. Biol. Chem. 267:22616-22623.

54. Gianni, M., et al. 1997. Stat 1 is induced and activated by all-trans retinoic acid in acute promyelocytic leukemia cells. Blood. 89:1001-1012.

55. Scott, L.M., Mueller, L., and Collins, S.J. 1996. E3, a hematopoietic-specific transcript directly regulated by the retinoic acid receptor $\alpha$. Blood. 88:2517-2530. 